\title{
MONITORAMENTO E CARACTERIZAÇÃO DA QUALIDADE DA ÁGUA DO RIO BENFICA COM VISTAS À SUA PRESERVAÇÃO
}

\section{J. S. M. NOGUEIRA ${ }^{1}$, L.F. SANTOS ${ }^{2}$}

${ }^{1}$ Escola de Engenharia de Lorena - USP

${ }^{2}$ Escola de Engenharia de Lorena - USP, Departamento de Engenharia Química

E-mail para contato: je.smnog@gmail.com

\begin{abstract}
RESUMO - A escassez de água, bem como a qualidade desse recurso indispensável para preservação da vida, é um problema que assola quase todos continentes. Faz-se, então, necessária a monitoração das propriedades da água dos rios a fim de possibilitar a realização de medidas de gestão ambiental; sendo este o objetivo deste trabalho, realizado com as águas do Rio Benfica, rio de classe 1, localizado no município de Piquete. Nesta pesquisa, os parâmetros físicoquímicos do corpo d'água, como OD, DBO, DQO, COT, Nitrogênio, Fósforo, entre outros, estão sendo analisados e os resultados, comparados com as leis federais estabelecidas para rios pertencentes a sua classe. Como resultado preliminar, tem-se que as águas do Rio Benfica se adequam, na maior parte das análises, à Resolução 357/05 do CONAMA para rios de classe 1 e que algumas análises exibiram um padrão de resultado que permite, até o momento, classificar os pontos localizados no centro da cidade (P3 e P4) como as áreas mais afetadas pela poluição; os situados ao final do município (P1 e P2) como áreas de contaminação intermediária e os localizados próximos às nascentes (P5, P6 e P7) como áreas pouco afetadas pelo despejo de poluentes. Para melhorar a qualidade da água desse rio, deveria ser avaliada a implantação de tratamento de esgoto na cidade de Piquete, uma vez que este resíduo possui a maior contribuição de poluentes para o corpo hídrico.
\end{abstract}

Palavras-chave: Monitoramento. Parâmetros. Qualidade. Água.

\section{INTRODUÇÃO}

A água é um recurso natural essencial para manter a vida na Terra e a sua escassez afeta quase todos os continentes. Logo, cada vez mais, vem se tornando necessária a preservação da qualidade, bem como o uso consciente e sustentável deste recurso.

A poluição dos recursos hídricos é causada pelo lançamento de rejeitos, de origem tanto doméstica quanto industrial, de forma indiscriminada nos corpos receptores. Esses efluentes, muitas vezes, são despejados nas águas dos rios sem o devido tratamento, afetando na sua qualidade e no equilíbrio do ecossistema aquático (SANTOS, 2006). Fato que pode ser observado até em rios de pequeno porte, como na bacia do Rio Benfica, situado no município de Piquete. Este rio é responsável por parte do abastecimento da cidade, além de receber, sem tratamento, uma porção do esgoto doméstico produzido em Piquete, o que gera impacto negativo em suas águas. Deve-se destacar que o Rio Benfica deságua do Rio Paraíba 
do Sul, que possui grande importância econômica para os estados de São Paulo, Minas Gerais e Rio de Janeiro.

Nesse contexto, este trabalho tem como objetivo monitorar e caracterizar a qualidade da água na bacia hidrográfica do Rio Benfica, visando melhorar o entendimento da dinâmica deste manancial, bem como auxiliar na definição de medidas de gestão ambiental da referida bacia.

\section{METODOLOGIA}

O Rio Benfica está localizado no município de Piquete - SP. Ele deságua no trecho paulista do rio Paraíba do Sul, que constitui o dreno natural da UGRHI 02, uma das bacias que o Estado de São Paulo dividiu para fins de aplicação da Política de Gestão de Recursos Hídricos, criada pela Lei Estadual $N^{\circ}$ 9.034, de 27/12/1994. Como tantas outras, a bacia do Rio Benfica, apesar de pertencer à classe 1, segundo o Decreto 10.755 de 22/11/1977, está sujeita à degradação ambiental, principalmente pelo crescimento acelerado de construções civis que surgem ao longo do rio, culminando em sua poluição pelos lançamentos de rejeitos sem tratamento, os quais não poderiam ser despejados em rio classe 1, de acordo com o Decreto 8.468 de 08/09/1976.

A coleta das amostras foi realizada em período de estiagem, em sete pontos prédefinidos (P1 a P7), sendo P1 na saída da cidade e P6 e P7 nas nascentes, conforme ilustrado na Figura 1. A disposição desses pontos foi determinada com o objetivo de conseguir avaliar a influência da contribuição doméstica e industrial do município.

Figura 1 - Pontos de coleta: de P1 a P7, no município de Piquete

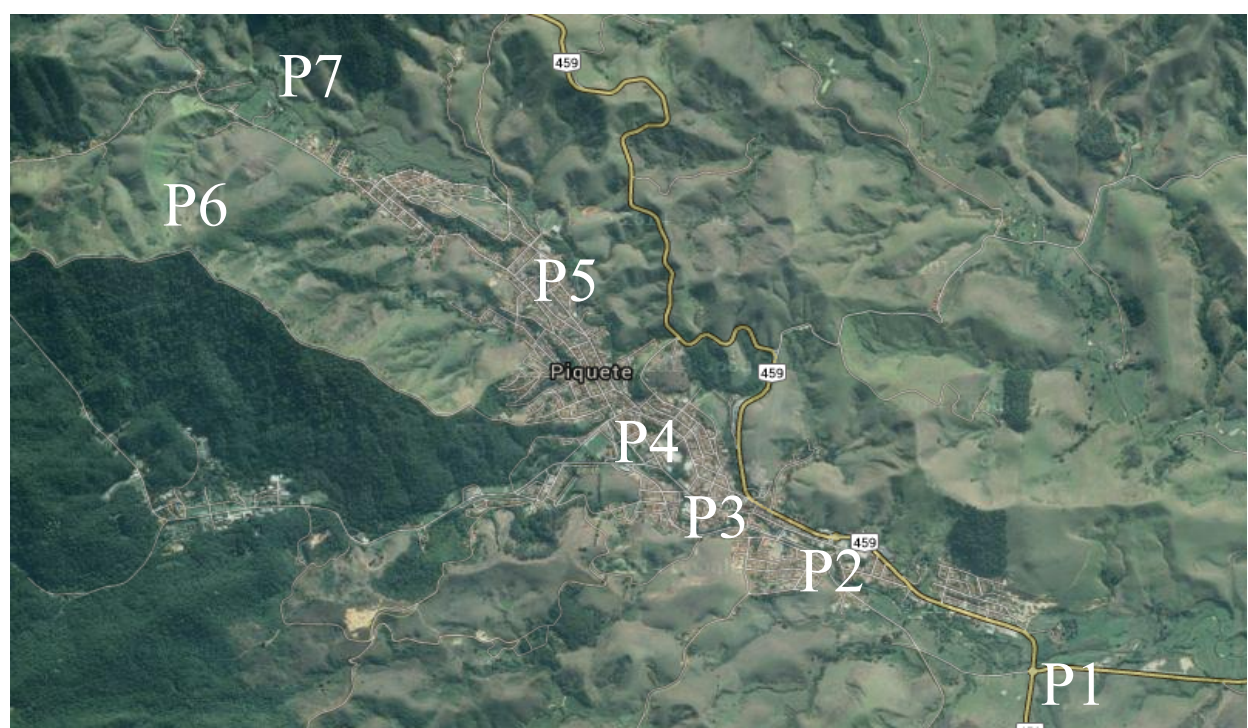

Fonte: GOOGLE MAPS (c2014)

As amostras foram caracterizadas em $\mathrm{pH}$, temperatura, condutividade elétrica, oxigênio dissolvido (OD), demandas química e bioquímica de oxigênio (DQO e DBO), turbidez, fósforo total, nitrogênio amoniacal e orgânico, carbono orgânico total (COT), fluoreto, cloreto, nitrato, sulfato e nitrito. A caracterização foi realizada no laboratório da Escola de 
Engenharia de Lorena - Universidade de São Paulo (EEL/USP), conforme APHA (American Public Health Association: Standard methods for the examination of water and wastewater).

As metodologias analíticas utilizadas foram validadas pelo método de dopagem da amostra e recuperação dos padrões adicionados.

\section{RESULTADOS E DISCUSSÕES}

Os resultados dos parâmetros determinados in situ ( $\mathrm{pH}$, condutividade e temperatura), dos ânions fluoreto, cloreto e sulfato, bem como o valor ideal de cada parâmetro para um rio de classe 1, determinado pela Resolução 357/05 do CONAMA, são encontrados na Tabela 1.

Tabela 1 - Resultados obtidos para $\mathrm{pH}$, condutividade, temperatura, fluoreto, cloreto e sulfato

\begin{tabular}{ccccccc}
\hline Amostras & $\mathrm{pH}$ & $\begin{array}{c}\text { Condutividade } \\
\left(\mu \mathrm{S} \mathrm{cm}^{-1}\right)\end{array}$ & $\begin{array}{c}\text { Temperatura } \\
\left({ }^{\circ} \mathrm{C}\right)\end{array}$ & $\begin{array}{c}\text { Fluoreto } \\
\left(\mathrm{mg} \mathrm{L}^{-1}\right)\end{array}$ & $\begin{array}{c}\text { Cloreto } \\
\left(\mathrm{mg} \mathrm{L}^{-1}\right)\end{array}$ & $\begin{array}{c}\text { Sulfato } \\
\left(\mathrm{mg} \mathrm{L}^{-1}\right)\end{array}$ \\
\hline P1 & 6,5 & 280 & 24,3 & 0,373 & 4,516 & 50,95 \\
P2 & 6,5 & 190 & 24,4 & 0,359 & 3,319 & 32,976 \\
P3 & 6,6 & 140 & 24,2 & 0,326 & 4,849 & 4,554 \\
P4 & 6,5 & 130 & 24,3 & 0,322 & 5,13 & 5,371 \\
P5 & 6,5 & 50 & 23,5 & 0,308 & 2,544 & 3,165 \\
P6 & 6,4 & 20 & 22,7 & 0,277 & 2,365 & 1,215 \\
P7 & 6,5 & 40 & 22,9 & 0,291 & 0,931 & 0,863 \\
CONAMA & $6,0-9,0$ & - & - & 1,4 & 250 & 250 \\
\hline
\end{tabular}

De acordo com a Tabela1, nota-se que os valores de $\mathrm{pH}$ se mantiveram praticamente constantes para todos os pontos e atendem à legislação vigente. Os dados de temperatura mantiveram-se abaixo da temperatura do dia da coleta $\left(27^{\circ} \mathrm{C}\right)$.

Os valores de condutividade variaram mais entre si, sendo que os pontos P1, P2, P3 e $\mathrm{P} 4$, localizados no centro e ao final da cidade, apresentaram resultados de condutividade superiores a $100 \mu \mathrm{S} / \mathrm{cm}$, indicando ambientes impactados, uma vez que este parâmetro representa, de maneira indireta, a concentração de poluentes (CETESB, 2013).

Os pontos P5, P6 e P7, no entanto, apresentaram melhores resultado para condutividade, confirmando que estes, localizados próximos à nascente, recebem menos descartes de poluentes que os anteriores. Além disso, foi possível perceber que a concentração de fluoreto manteve-se praticamente constante em todos os pontos de coleta e todos apresentaram resultados abaixo do limite estabelecido pela resolução CONAMA 357/05. Cloreto e sulfato também apresentaram concentrações consideravelmente abaixo da permitida por essa resolução.

A Tabela 2 apresenta os resultados obtidos para as análises de oxigênio dissolvido (OD), demandas química e bioquímica de oxigênio (DQO e DBO), carbono orgânico total (COT) e turdibez. 
Tabela 2 - Resultados obtidos para OD, COT, DQO, DBO e turbidez

\begin{tabular}{cccccc}
\hline Amostras & $\begin{array}{c}\text { OD } \\
\left(\mathrm{mg} \mathrm{L}^{-1}\right)\end{array}$ & $\begin{array}{c}\mathrm{COT} \\
\left(\mathrm{mg} \mathrm{L}^{-1}\right)\end{array}$ & $\begin{array}{c}\text { DQO } \\
\left(\mathrm{mg} \mathrm{L}^{-1}\right)\end{array}$ & $\begin{array}{c}\text { DBO } \\
\left(\mathrm{mg} \mathrm{L}^{-1}\right)\end{array}$ & $\begin{array}{c}\text { Fósforo total } \\
\left(\mathrm{mg} \mathrm{L}^{-1}\right)\end{array}$ \\
\hline P1 & 6,877 & 9,757 & 12,57 & 1,672 & 0,0644 \\
P2 & 6,751 & 10,20 & 25,40 & 2,240 & 0,0613 \\
P3 & 4,038 & 13,41 & 30,18 & 4,953 & 0,0829 \\
P4 & 5,741 & 13,93 & 40,49 & 5,457 & 0,0798 \\
P5 & 7,319 & 8,093 & 6,78 & 0,883 & 0,0367 \\
P6 & 7,697 & 6,839 & 10,31 & 0,189 & 0,0336 \\
P7 & 7,445 & 6,993 & 11,31 & 1,136 & 0,0459 \\
CONAMA & $\geq 6$ & - & - & $\leq 3$ & 0,1 \\
\hline
\end{tabular}

A partir dos dados apresentados pela Tabela 2, pode-se notar que todas as análises mantiveram o mesmo perfil de resultados, isto é, os pontos P3 e P4, localizados no centro da cidade, apresentaram as maiores concentrações, P1 e P2, situados ao fim do município, concentrações intermediárias, enquanto os pontos localizados próximos a nascente (P5, P6 e P7) apresentaram as menores.

Sendo assim, pode-se dizer que P3 e P4 apresentam grau de poluição, oriunda de matéria orgânica, maior que os outros pontos. Este resultado foi obtido, possivelmente, porque a montante de ambos os pontos existem despejos de esgoto e segundo o relatório da Qualidade das águas superficiais no estado de São Paulo da CETESB (2013), Piquete não possui tratamento de esgoto, logo, a carga orgânica decomposta nesses pontos faz com que OD diminua, enquanto os demais parâmetros aumentam.

Comparando os resultados obtidos com a Resolução 357/05 do CONAMA para um rio classe 1, verificou-se que, tanto para OD quanto para $\mathrm{DBO}$, todos os pontos, com exceção de P3 e P4, se adequam à exigência do CONAMA. Com relação ao parâmetro fósforo total, pode-se perceber que todos os pontos apresentaram valores abaixo do máximo permitido pela resolução.

Os resultados dos parâmetros nitrogênio amoniacal e orgânico, nitrato, nitrito e turbidez, assim como os valores estipulados pela Resolução 357/05 do CONAMA para cada um, estão presentes na Tabela 3.

Tabela 3 - Resultados obtidos para fósforo total, nitrogênio amoniacal e orgânico, nitrato e nitrito

\begin{tabular}{cccccc}
\hline Amostras & $\begin{array}{c}\text { Nitrogênio Amoniacal } \\
\left(\mathrm{mg} \mathrm{L}^{-1}\right)\end{array}$ & $\begin{array}{c}\text { Nitrogênio Orgânico } \\
\left(\mathrm{mg} \mathrm{L}^{-1}\right)\end{array}$ & $\begin{array}{c}\text { Nitrato } \\
\left(\mathrm{mg} \mathrm{L}^{-1}\right)\end{array}$ & $\begin{array}{c}\text { Nitrito } \\
\left(\mathrm{mg} \mathrm{L}^{-1}\right)\end{array}$ & $\begin{array}{c}\text { Turbidez } \\
(\mathrm{UNT})\end{array}$ \\
\hline P1 & 1,930 & 0,056 & 13,485 & 10,5 & 4,68 \\
P2 & 1,787 & 0,104 & 10,125 & 0,379 & 9,73 \\
P3 & 3,509 & 0,142 & 1,466 & 0 & 3,83 \\
P4 & 1,821 & 0,099 & 1,678 & 0 & 6,09 \\
P5 & 0,071 & 0,052 & 1,258 & 0 & 0,62 \\
P6 & 0,000 & 0,000 & 1,084 & 0 & 0 \\
P7 & 0,000 & 0,000 & 0,861 & 0 & 0 \\
CONAMA & 3,7 para $\mathrm{pH} \leq 7,5$ & - & 10 & 1 & $\leq 40$ \\
\hline
\end{tabular}


Todos os pontos apresentaram concentração de nitrogênio amoniacal dentro do limite determinado pelo CONAMA. Além disso, observou-se que os níveis de nitrato e nitrito nos pontos P3, P4, P5, P6 e P7, estão adequados, enquanto que em P2, a concentração de nitrato se apresenta ligeiramente acima do permitido e em P1 ambos os íons apresentam concentrações que superam o limite máximo estabelecido pela legislação, exibindo um resultado preocupante, já que o nitrato pode causar a metahemoglobinemia infantil, doença letal para crianças (CETESB, 2013).

No ponto P3 obtiveram-se os maiores valores de concentração para as formas amoniacal e orgânica do nitrogênio, indicando proximidade do foco de poluição; enquanto P1, para as formas iônicas (nitrato e nitrito), apontando que este ponto encontra-se mais distante fonte poluidora (CETESB, 2013). Esta afirmação está de acordo com a dinâmica do rio, uma vez que o ponto P3, por estar localizado no centro do município de Piquete, recebe as descargas de esgoto da cidade, enquanto P1, por estar situado ao final da cidade, está mais afastado do local de despejo.

Com relação ao parâmetro turbidez, pode-se perceber que todos os pontos apresentaram valores consideravelmente abaixo do máximo permitido pela lei, indicando pouca presença de partículas em suspensão, normalmente oriundas de esgotos domésticos e efluentes industriais (CETESB, 2013).

Após término das análises para cada ponto, a amostra de água de P3, ponto que apresentou os piores resultados na maior parte dos estudos, foi dopada e utilizada na validação de algumas das metodologias. Nesse processo, foi feito a validação de DBO, DQO, COT, nitrogênio amoniacal e fósforo total, e seus resultados foram apresentados na Tabela 4.

Tabela 4 - Resultado da validação de DQO, DBO, COT, Nitrogênio amoniacal e Fósforo

\begin{tabular}{cccccc}
\hline Resultado & $\begin{array}{c}\mathrm{DQO} \\
\left(\mathrm{mg} \mathrm{L}^{-1}\right)\end{array}$ & $\begin{array}{c}\mathrm{DBO} \\
\left(\mathrm{mg} \mathrm{L}^{-1}\right)\end{array}$ & $\begin{array}{c}\mathrm{COT} \\
\left(\mathrm{mg} \mathrm{L}^{-1}\right)\end{array}$ & $\begin{array}{c}\text { Nitrogênio amoniacal } \\
\left(\mathrm{mg} \mathrm{L}^{-1}\right)\end{array}$ & $\begin{array}{c}\text { Fósforo Total } \\
\left(\mathrm{mg} \mathrm{L}^{-1}\right)\end{array}$ \\
\hline Validação & 893,45 & 441,77 & 295,84 & 19,25 & 54,13 \\
Esperado & 890 & 420 & 290 & 20 & 50 \\
\hline
\end{tabular}

Pelos dados da Tabela 4, pode-se verificar que os resultados obtidos na validação estão bastante próximos dos, esperados, indicando que as metodologias foram corretamente realizadas.

\section{CONCLUSÃO}

Com base nos resultados preliminares dos parâmetros analisados neste projeto, observou-se que, no geral, a água do Rio Benfica atende à Resolução 357/05 do CONAMA para rio de classe 1, apresentando alguns pontos com valores acima do permitido em determinadas análises.

Além disso, pode-se verificar que a DQO, DBO, COT, OD, Nitrogênio Amoniacal e Orgânico exibiram um padrão de resultados, indicando que os pontos $\mathrm{P} 3$ e P4, localizados no centro da cidade de Piquete, são as áreas mais afetadas pela poluição; P1 e P2, localizados ao final da cidade, constituem as áreas com contaminação intermediária; e os pontos P5, P6 e P7, localizados próximos às nascentes, consistem nas áreas menos poluídas. 
Embora haja fiscalização, a mata nativa que compõe a bacia hidrográfica do Rio Benfica vem aos poucos sendo degradada, reduzindo, assim, consideravelmente o volume de água das nascentes. Para melhorar a qualidade da água desse rio, deveria ser avaliada a implantação de tratamento de esgoto na cidade de Piquete, uma vez que este resíduo possui a maior contribuição de poluentes para o corpo hídrico.

\section{REFERÊNCIAS}

AMERICAN PUBLIC HEALTH ASSOCIATION - APHA: Standard methods for the examination of water and wastewater. 20th ed. Washington: American Public Health Association, 1998.

BRASIL. Ministério do Meio Ambiente. Conselho Nacional do Meio Ambiente (CONAMA). Resolução $n^{\circ}$ 357, de 17 de março de 2005 (Alterada pela Resolução ${ }^{\circ}$ 410/2009 e pela $\left.\mathrm{n}^{\circ} 430 / 2011\right)$. Dispõe sobre a classificação dos corpos de água e diretrizes ambientais para o seu enquadramento, bem como estabelece as condições e padrões de lançamento de efluentes, e dá outras providências. Diário Oficial da União, Brasília, 18 mar.2005.

COMPANHIA ESTADUAL DE TECNOLOGIA DE SANEAMENTO AMBIENTAL CETESB. Qualidade das águas superficiais no estado de São Paulo. São Paulo: CETESB, 2013.

GOOGLE MAPS. Google. Dados do mapa. C2014. Disponível em $<$ https://www.google.com.br/maps/@,-22610194,5.1847778,3542m/data=!3m1!1e3> Acesso em: 10 set. 2014.

SÃO PAULO (Estado). Decreto $\mathrm{n}^{\circ}$ 8.468, de 08 de setembro de 1976 (Atualizado com redação dada pelo Decreto 54.487, de 26/06/09). Aprova o Regulamento da Lei $n^{\circ} 997$, de 31 de maio de 1976, que dispõe sobre a prevenção e o controle da poluição do meio ambiente. São Paulo, 1976.

. Decreto $\mathrm{n}^{\mathrm{o}} 10.755$, de 22 de novembro de 1977. Dispõe sobre o enquadramento dos corpos de água receptores na classificação prevista no Decreto $\mathrm{n}^{\circ} 8.468$, de 8 de setembro de 1976, e dá providências correlatas. São Paulo, 1977.

. Lei $\mathrm{n}^{\circ}$ 9034, de 27 de dezembro de 1994. Dispõe sobre o Plano Estadual de Recursos Hídricos - PERH, a ser implantado no período 1994 e 1995. São Paulo, 1994.

SANTOS, L.F. Caracterização e tratamento de efluentes da fabricação de nitrocelulose. Lorena, 2006. 102 fls. Tese (Doutorado em Biotecnologia Industrial) - Escola de Engenharia de Lorena. Lorena. 2006. 